\title{
Temporal trend and spatial distribution of acute lymphoblastic leukemia in Iranian children during 2006-2014: a mixed ecological study
}

\author{
Sajjad Rahimi Pordanjani ${ }^{1}$, Amir Kavousi ${ }^{1,2}$, Babak Mirbagheri ${ }^{3}$, Abbas Shahsavani ${ }^{4,5}$, \\ Koorosh Etemad' \\ ${ }^{1}$ Department of Epidemiology, School of Public Health and Safety, Shahid Beheshti University of Medical Sciences, Tehran, Iran; ${ }^{2}$ Workplace \\ Health Promotion Research Center, School of Public Health and Safety, Shahid Beheshti University of Medical Sciences, Tehran, Iran; ${ }^{3}$ Center \\ for Remote Sensing and GIS Research, Faculty of Earth Sciences, Shahid Beheshti University, Tehran, Iran; ${ }^{4}$ Environmental and Occupational \\ Hazards Control Research Center, Shahid Beheshti University of Medical Sciences, Tehran, Iran; ${ }^{5}$ Department of Environmental Health \\ Engineering, School of Public Health and Safety, Shahid Beheshti University of Medical Sciences, Tehran, Iran
}

OBJECTIVES: The present study investigated the spatiotemporal epidemiological status of acute lymphoblastic leukemia (ALL), the most common childhood cancer, in Iran.

METHODS: Using an exploratory mixed design, this ecological study examined 3,769 under-15 children with ALL recorded in the National Cancer Registry of Iran during 2006-2014. Data were analyzed using the Mann-Whitney U test, the Getis-Ord general G (GOGG) index, optimized hot spot analysis, and Pearson correlation coefficients (PCC) at a significance level of 0.05 .

RESULTS: The average annual incidence of the disease was 2.25 per 100,000 under-15 children, and the cumulative incidence rate (CIR) was 21.31 per 100,000 under-15 children. Patients' mean age was 5.90 years (standard deviation, 3.68), and the peak incidence was observed among 2-year to 5-year-olds. No significant difference was found in mean age between boys and girls $(\mathrm{p}=0.261)$. The incidence of ALL was more common during spring and summer than in other seasons. The GOGG index was 0.039 and significant $(\mathrm{p}<0.001)$. Hot spots were identified in south, central, and eastern Iran and cold spots in the north and west of Iran. The PCC between the CIR and latitude was negative $(\mathrm{r}=-0.507 ; \mathrm{p}=0.003)$ but that between the CIR and longitude was positive ( $\mathrm{r}=0.347 ; \mathrm{p}=0.055)$.

CONCLUSIONS: The incidence of ALL in Iranian children was lower than that observed in developed countries, but showed an increasing trend. It can be argued that the incidence of ALL is due to synergistic interactions between environmental, infectious, geographical, and genetic risk factors.

KEY WORDS: Leukemia, Incidence, Spatial, Temporal, Iran

\section{Correspondence: Koorosh Etemad}

Department of Epidemiology, School of Public Health and Safety, Shahid Beheshti University of Medical Sciences, Velenjak Street, Tehran 198353-5511, Iran

E-mail: etemadk@sbmu.ac.ir

Received: Jun 22, 2020 / Accepted: Jul 29, 2020 / Published: Jul 29, 2020

This article is available from: https://e-epih.org/

(c) This is an open-access article distributed under the terms of the Creative Commons Attribution License (https://creativecommons.org/licenses/by/4.0/), which permits unrestricted use, distribution, and reproduction in any medium, provided the original work is properly cited.

(C) 2020, Korean Society of Epidemiology

\section{INTRODUCTION}

The most common type of childhood cancer, both worldwide and in Iran, is acute lymphoblastic leukemia (ALL) [1]. According to a 2014 report from the National Cancer Registry of Iran, the age-standardized incidence rate of leukemia is 6.84 per 100,000 persons [2]. With its high incidence and prevalence, leukemia leads to significant mortality and very high direct (US\$15,026.6) and indirect (US\$932.3) costs in Iran [3].

Leukemia is a multifactorial disease, and despite the advances in medical sciences, the main causes of its occurrence remain un- 
known $[4,5]$. The hypothesis that infectious factors play a role in the development of ALL (the infectious hypothesis) has yet to be confirmed; however, identifying seasonal patterns and spatial clusters could provide support for this possibility [6-8].

Spatiotemporal analyses are important tools for monitoring, controlling, and surveilling childhood cancer and can be very effective for generating new hypotheses $[6,9,10]$. Studies on spatial clustering of childhood leukemia can help identify potential sources of contamination and assist in the search for new clues about environmental risk. The question of whether leukemia shows clusters remains a scientific challenge. Previous studies have published inconsistent results; 2 studies showed no evidence of disease clustering [11,12], 2 studies observed significant clustering in at least 1 subgroup [5,13], and 6 studies found statistically significant overall clustering [4,7,9,14-16].

Controlling cancer is a top priority for health care systems. Knowledge of temporal trends, spatial patterns, and high-risk disease areas is one of the most important aspects of epidemiological studies and research into the etiology of cancer. These are essential prerequisites for health care management decision-making and the disease surveillance system.

Therefore, since the principal cause of ALL is unknown and the epidemiological status of ALL is a research gap that remains to be filled, the present study was conducted to investigate temporal trends and spatial patterns of ALL in Iran, and to acquire a better understanding of the risk factors affecting the disease cycle.

\section{MATERIALS AND METHODS}

\section{Study design and type}

This ecological study with an exploratory mixed design was conducted among 3,769 under-15 children with ALL in Iran from 2006 to 2014. The term "exploratory" refers to studies that explore and describe temporal trends and spatial patterns of disease incidence. This study used a mixed design, meaning that it simultaneously investigated the impact of place (a multiple-group study) and time (a time-trend study) [17].

\section{Target population and study population}

The target population was all children with ALL in Iran. The study population included children diagnosed with ALL from 2006 to 2014 in the National Cancer Registry of Iran who met the inclusion criteria, which were a diagnosis of ALL, age less than 15 years, and accessible spatial information.

\section{Data collection sources}

Three types of data sources were used. Patient data were obtained from the National Cancer Registry of Iran from 2006 to 2014. Data on the population of under-15 children (the population at risk) in all provinces in Iran were obtained from the Iranian Statistics Center. The geographic coordinates of the patients were obtained from the latest information available in Google Maps and georeferenced with the layer of provinces in Iran.

\section{Description of the study area}

Iran is a Middle Eastern country in southwest Asia with an area of $1,648,195 \mathrm{~km}^{2}$. Iran's latitude extends from $25^{\circ} 3^{\prime}$ to $39^{\circ} 47^{\prime}$ north and its longitude ranges from $44^{\circ} 5^{\prime}$ and $63^{\circ} 18^{\prime}$ east (Figure 1 ). According to the latest census in 2016, the population of Iran is estimated to be $79,927,270$.

\section{Statistical analysis}

The statistical analysis consisted of three main parts: a descriptive analysis, a temporal trend analysis, and a spatial pattern analysis. All statistical tests were performed with a 2-sided alpha of 0.05 .

\section{Descriptive analysis}

For the descriptive analysis of data, the central tendency and dispersion indices of the disease were calculated, and then the average annual incidence and cumulative incidence rate (CIR) of ALL in each province of Iran from 2006 to 2014 were calculated.

\section{Temporal trend analysis}

To evaluate the temporal trend of ALL, the incidence of new cases was determined by year, month, patients' age, and patients' sex from 2006 to 2014, and then the temporal trend was plotted and evaluated using GraphPad Prism version 8.4.2 (GraphPad, San Diego, CA, USA). The Mann-Whitney U test was used in SPSS version 16 (SPSS Inc., Chicago, IL, USA) to compare the mean age between male and female patients.

\section{Spatial pattern analysis and cluster identification}

To evaluate the spatial patterns of ALL, the CIR from 2006 to 2014 for all provinces was first generated in ArcGIS version 10.3 (Esri, Redlands, CA, USA) from 2006 to 2014. Next, these patterns were evaluated using the Getis-Ord general G (GOGG) index and optimized hot spot analysis (OHSA).

\section{Getis-Ord general G}

The GOGG index was developed by Getis and Ord as a global statistic for measuring spatial patterns. The GOGG index indicates the degree and amount of clustering of high and low values. If the GOGG value obtained by this method is higher than the expected value and the Z-score is positive, it indicates a tendency for high values to cluster. However, if the GOGG value is lower than expected and the Z-score is negative, it indicates a tendency for low values to cluster. The null hypothesis in GOGG is generally the absence of spatial clustering in the region [18]. In the next stage, the optimized Getis-Ord Gi* was used to identify hot spots and cold spots in different regions of Iran.

\section{Optimized hot spot analysis}

OHSA is a more accurate, more precise, and newer method for detecting clusters. This method is based on the Getis-Ord Gi*, with the distance band optimized for hot spots and cold spots. The Getis-Ord $\mathrm{Gi}^{*}$ is an index for dividing polygons based on the 


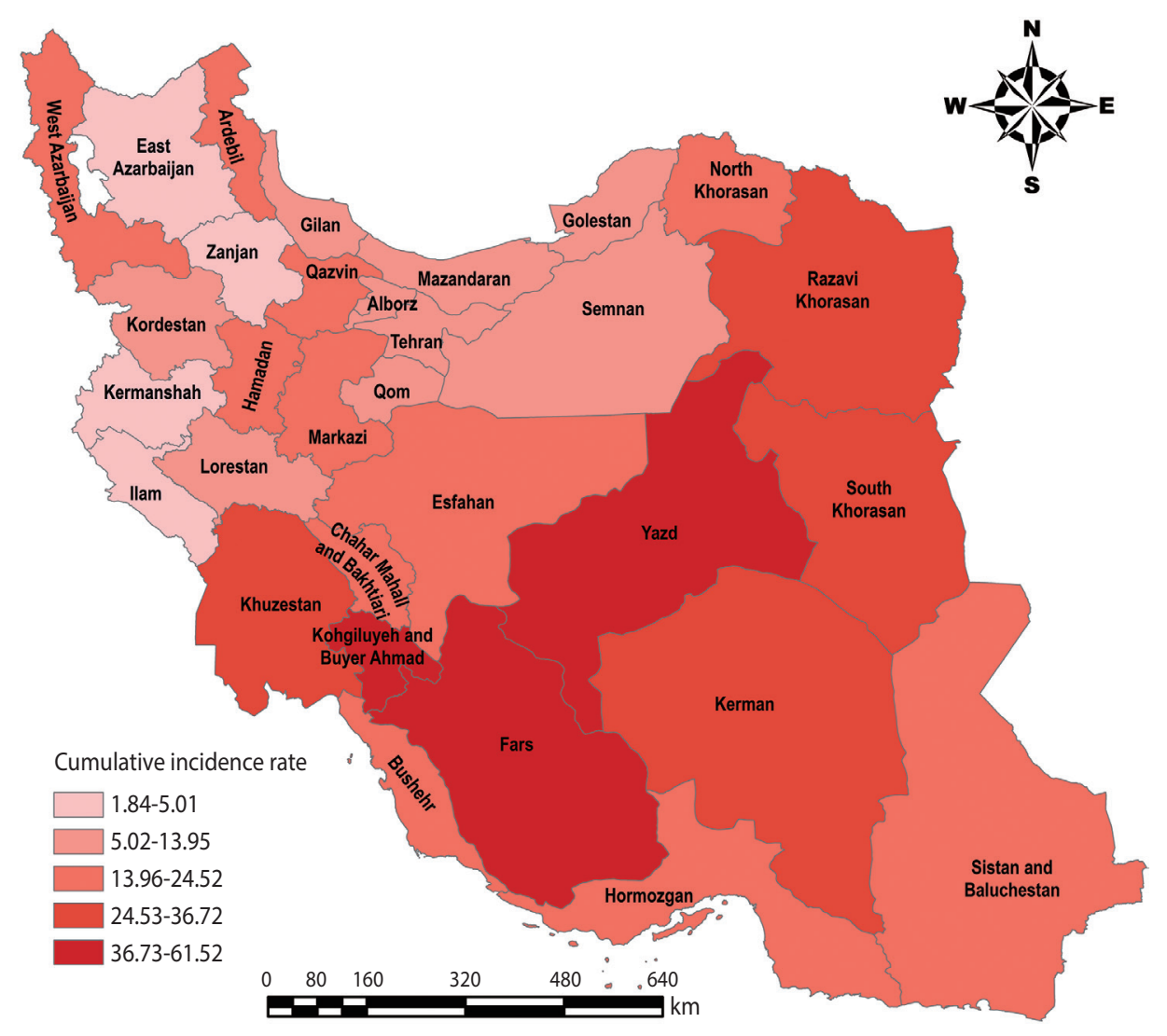

Figure 1. Geographical location of the study area.

Z-score and p-value. If the Z-score is positive and high, it indicates the accumulation of high values and the formation of a high-risk cluster, known as a hot spot. In contrast, a negative and low Z-score indicates the accumulation of low values and the formation of a low-risk cluster, which is known as a cold spot. Next, the p-value is calculated to determine the precision and significance level of an identified cluster. For hot spots, the higher the Z-score and the lower the p-value, the less likely a cluster is to be random. For cold spots, the lower the Z-score and the lower the p-value, the less likely a cluster is to be random. If the Z-score is near zero, no spatial clustering is present. OHSA automatically selects the optimal distance band value at which clustering intensity is maximized based on the incremental spatial autocorrelation method and uses it as an analysis scale for the Getis-Ord $\mathrm{Gi}^{*}$ statistic. Thus, this method shows the best possible outputs for identifying hot spots and cold spots, which can be displayed at 90\%, 95\%, and 99\% confidence levels (Cl) [19].

\section{Correlation analysis}

Finally, to evaluate the correlation between the CIR of ALL with the geographical coordinates of patients' residence, Pearson correlation coefficients (PCCs) and scatter plots with a line of best fit (95\% confidence interval) were used.

\section{Ethics statement}

Ethical approval was obtained from the Shahid Beheshti University of Medical Sciences Ethics Committee (No.IR.SBMU. PHNS. REC.1398.143).

\section{RESULTS}

\section{Descriptive}

After applying the inclusion and exclusion criteria, 3,769 ALL patients were included. The average annual incidence of ALL was 2.25 per 100,000 children under the age of 15 years, and $57.9 \%$ $(n=2,182)$ of the incident cases were in boys, resulting in a sex ratio of boys to girls of 1.37. The mean and standard deviation of patients' age were $3.68 \pm 5.90$ years, and the median age was 5 years. The number of incident cases and CIR of ALL in each province of Iran from 2006 to 2014 are shown in Table 1. Overall, the CIR of the disease in Iran during 2006 to 2014 was 21.315 per 100,000 children under the age of 15 years.

\section{Temporal trend}

The temporal trend of annual incident cases of ALL from 2006 to 2014 is shown in Figure 2. The annual number of new cases increased during this period from 269 cases in 2006 to 615 cases in 2014 (by 2.28 times). The incidence of new cases in boys was 
Table 1. Cumulative incidence rate (CIR) of acute lymphoblastic leukemia in the provinces of Iran from 2006 to 2014

\begin{tabular}{|c|c|c|c|c|c|c|c|c|c|}
\hline No. & Province name & $\begin{array}{c}\text { No. of } \\
\text { incident } \\
\text { cases }\end{array}$ & $\begin{array}{l}\text { Population } \\
\text { under- } 15 \mathrm{yr}\end{array}$ & $\begin{array}{c}\text { CIR per } \\
10^{6}\end{array}$ & No. & Province name & $\begin{array}{c}\text { No. of } \\
\text { incident } \\
\text { cases }\end{array}$ & $\begin{array}{l}\text { Population } \\
\text { under-15 yr }\end{array}$ & $\begin{array}{c}\text { CIR per } \\
10^{6}\end{array}$ \\
\hline 1 & Alborz & 56 & 432,664 & 12.943 & 17 & Kurdistan & 34 & 383,948 & 8.855 \\
\hline 2 & Ardebil & 68 & 322,597 & 21.079 & 18 & Lorestan & 53 & 452,065 & 11.724 \\
\hline 3 & Bushehr & 92 & 375,228 & 24.518 & 19 & Markazi & 61 & 313,602 & 19.451 \\
\hline 4 & Chahar Mahall and Bakhtiari & 37 & 233,466 & 15.848 & 20 & Mazandaran & 87 & 623,446 & 13.955 \\
\hline 5 & East Azerbaijan & 33 & 831,490 & 3.969 & 21 & North Khorasan & 39 & 243,808 & 15.996 \\
\hline 6 & Isfahan & 213 & $1,008,302$ & 21.125 & 22 & Qazvin & 45 & 230,359 & 19.535 \\
\hline 7 & Fars & 620 & $1,007,730$ & 61.524 & 23 & Qom & 30 & 276,229 & 10.861 \\
\hline 8 & Gilan & 54 & 515,215 & 10.481 & 24 & Razavi Khorasan & 459 & $1,504,854$ & 30.501 \\
\hline 9 & Golestan & 53 & 442,656 & 11.973 & 25 & Semnan & 15 & 133,436 & 11.241 \\
\hline 10 & Hamadan & 93 & 410,381 & 22.662 & 26 & Sistan and Baluchestan & 176 & 880,028 & 19.999 \\
\hline 11 & Hormozgan & 108 & 686,490 & 15.732 & 27 & South Khorasan & 45 & 163,526 & 27.519 \\
\hline 12 & Ilam & 7 & 139,818 & 5.007 & 28 & Tehran & 249 & $2,443,481$ & 10.190 \\
\hline 13 & Kerman & 239 & 684,095 & 34.937 & 29 & West Azerbaijan & 143 & 761,508 & 18.779 \\
\hline 14 & Kermanshah & 8 & 435,241 & 1.838 & 30 & Yazd & 113 & 242,802 & 46.540 \\
\hline 15 & Khuzestan & 433 & $1,179,140$ & 36.722 & 31 & Zanjan & 12 & 252,213 & 4.758 \\
\hline 16 & Kohgiluyeh and Buyer Ahmad & 94 & 171,480 & 54.817 & \multicolumn{2}{|c|}{ Total population of Iran } & 3,769 & $17,681,629$ & 21.315 \\
\hline
\end{tabular}

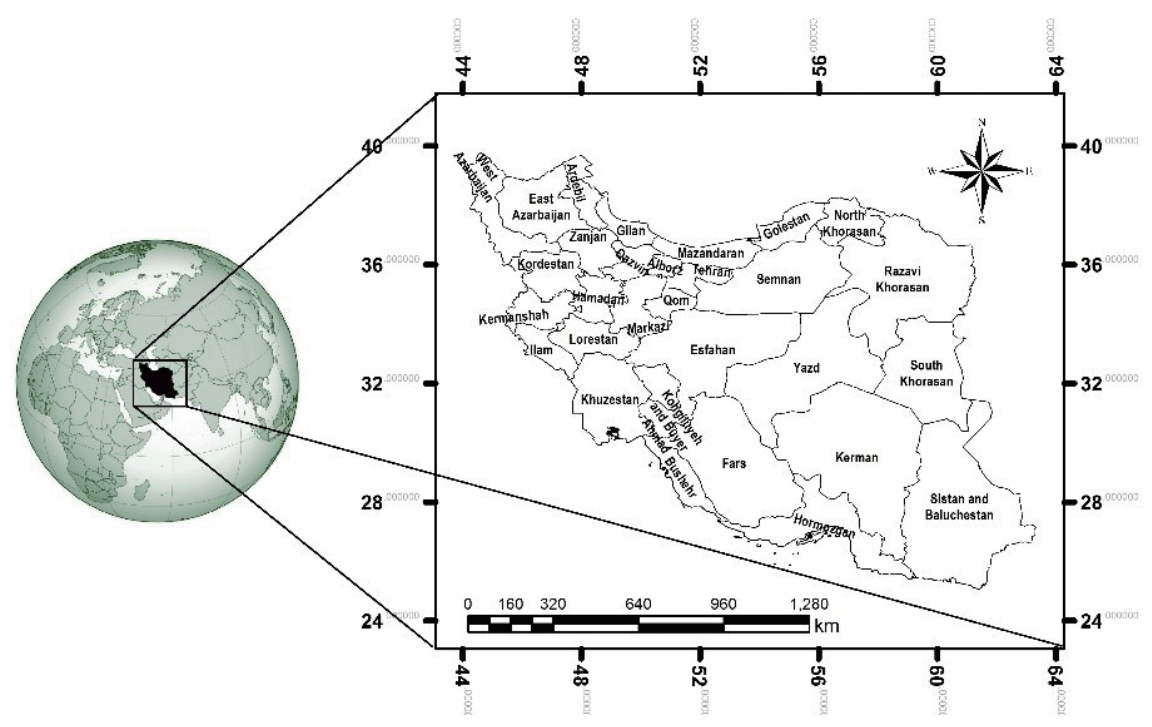

Figure 2. Temporal trend of incident acute lymphoblastic leukemia cases from 2006 to 2014.

higher than in girls in all years studied.

Figure 3 shows the temporal trends of incident ALL cases by age. The highest incidence of new cases was in children between 2 years and 5 years of age. The graph shows that the lowest frequency of new cases was around birth $(n=85)$. The incidence peaked at 3 years of age $(n=488)$, and then decreased gradually from 3 years to 14 years. The age distribution of incident cases in boys and girls was right-skewed; therefore, the Mann-Whitney $\mathrm{U}$ test was used to compare the mean age of ALL in girls and boys. The mean age was similar in both sexes, with no statistically significant difference $(\mathrm{p}=0.261)$.
Seasonal variation was found in the month of diagnosis, with spring $(\mathrm{n}=1,088)$ accounting for more cases than summer $(\mathrm{n}=$ $957)$, winter $(n=896)$, and autumn $(n=828)$. The highest number of new cases was reported in June $(n=377)$, and the lowest number in November $(n=242)$.

\section{Spatial pattern and cluster identification}

Figure 4 shows the spatial pattern of the CIR of ALL from 2006 to 2014 .

The GOGG index was 0.039 and significant $(\mathrm{p}<0.001)$, indicating a tendency for high incidence rates (hot spots) to cluster. 


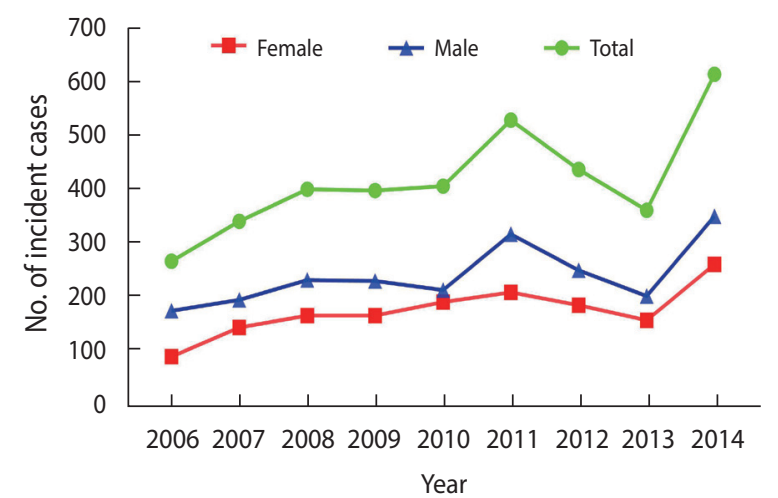

Figure 3. Distribution of new cases of acute lymphoblastic leukemia by age between 2006 and 2014 .

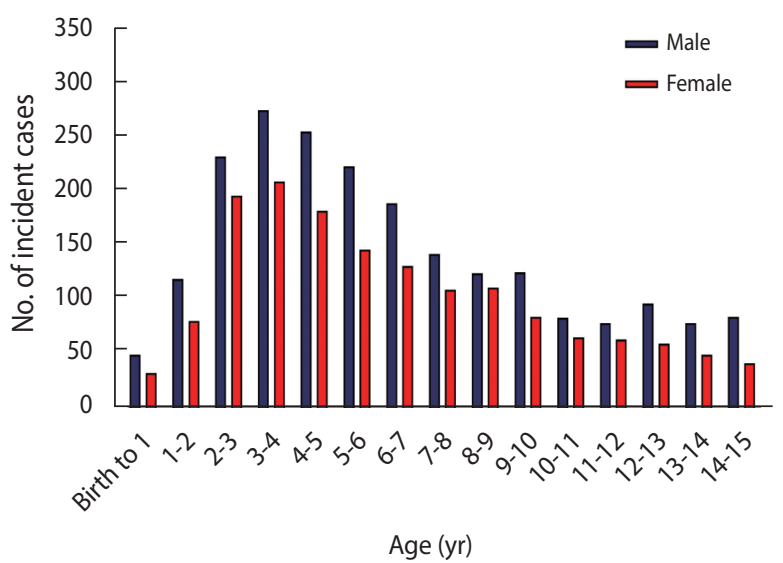

Figure 4. Cumulative incidence rate of acute lymphoblastic leukemia during 2006-2014 in Iran.

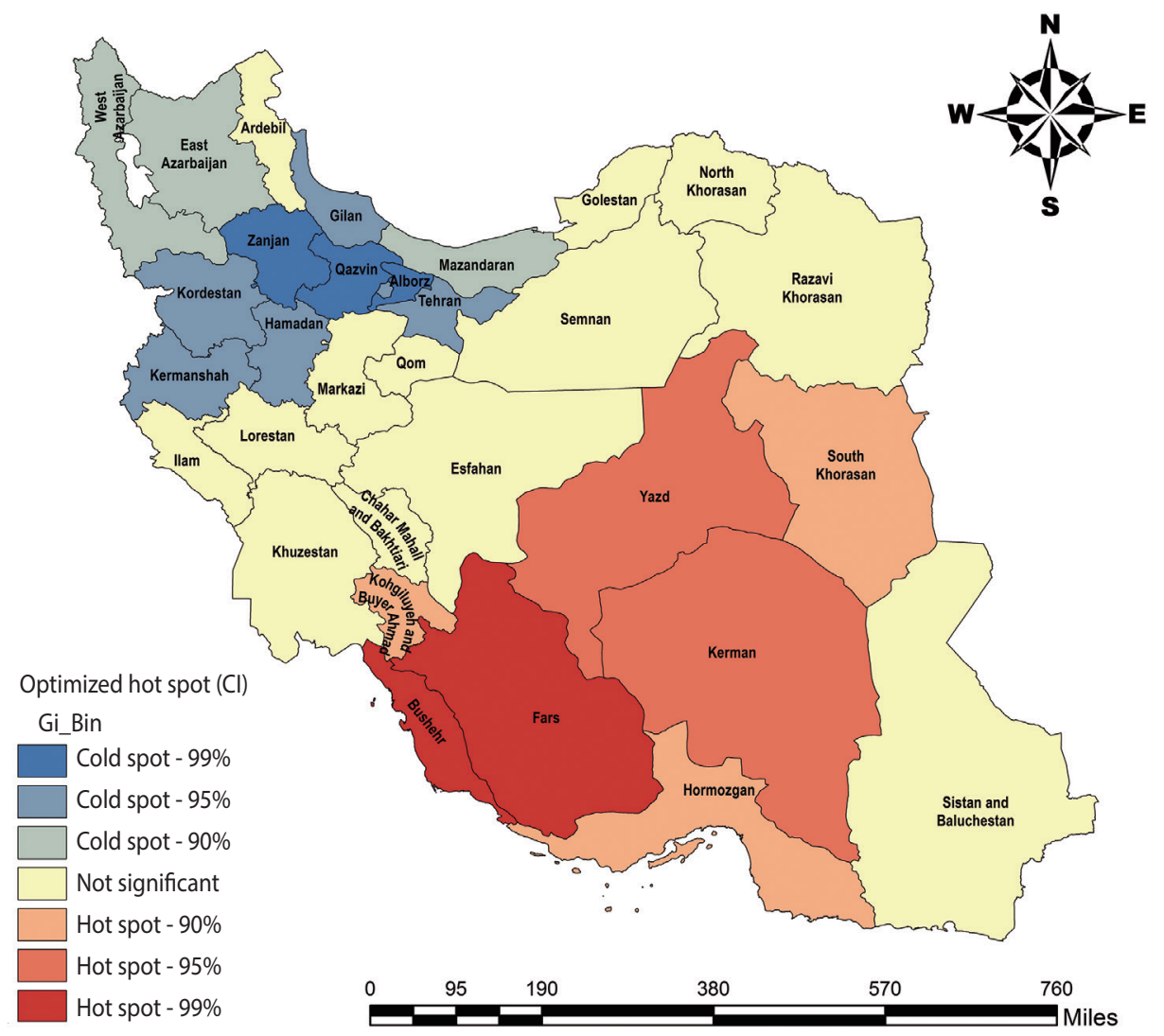

Figure 5. Hot spots (clusters of high values) and cold spots (clusters of low values) of acute lymphoblastic leukemia in Iran using optimized hot spot analysis. $\mathrm{Cl}$, confidence level.

The optimal bandwidth was estimated based on OHSA to be $448.6 \mathrm{~km}$. The identified hot spots in Fars and Bushehr Provinces $(99 \% \mathrm{Cl})$, Yazd and Kerman $(95 \% \mathrm{Cl})$ and Kohgiluyeh and Boyer Ahmad, South Khorasan and Hormozgan $(90 \% \mathrm{Cl})$. Moreover, it identified cold spots in Zanjan, Alborz, and Qazvin Provinces (99\% Cl) and Kermanshah, Hamedan, Kurdistan, Tehran and Gi- lan $(95 \% \mathrm{Cl})$ and West Azerbaijan, East Azerbaijan and Mazandaran $(90 \% \mathrm{Cl}$ ) (Figure 5). All of the cold spots were located in the north and west of Iran (lower longitude and higher latitude), and all of the hot spots were located in southern, central, and eastern Iran (higher longitude and lower latitude).

The PCC between the CIR and the latitude and longitude of 

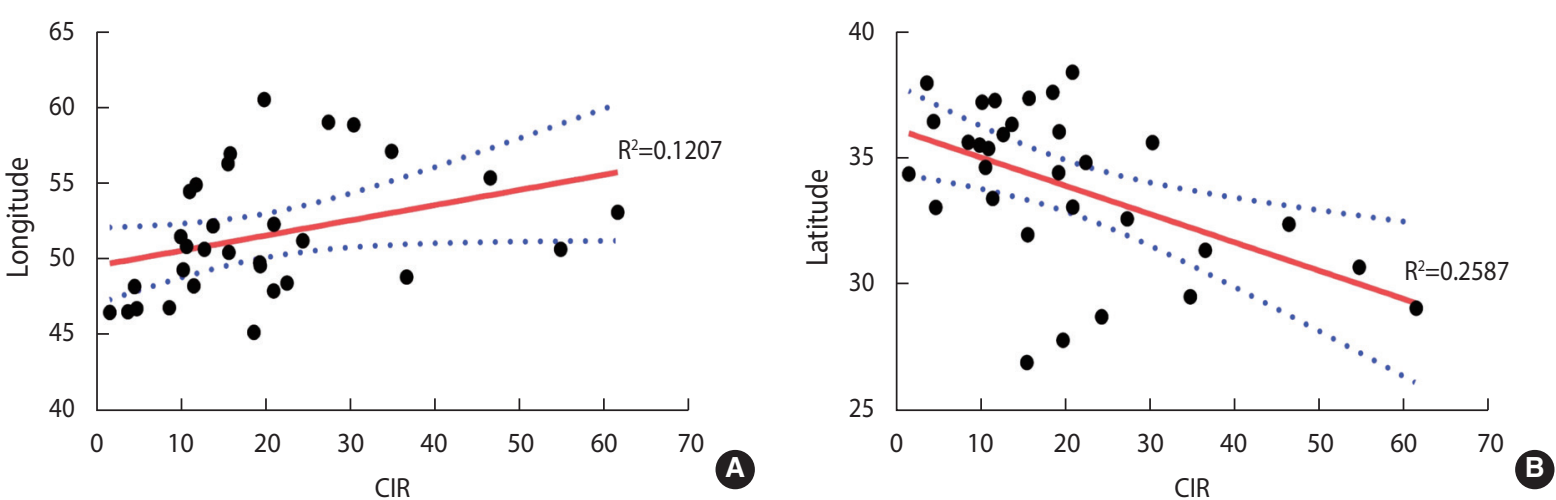

Figure 6. Scatter plot and line of best fit (95\% confidence interval) for the correlations between the cumulative incidence rate (CIR) of acute lymphoblastic leukemia with longitude (A) and latitude (B).

patients' residence was used to assess whether ALL incidence was correlated with the geographic coordinates of patients' residence. The PCC between the CIR and latitude was negative and significant $(r=-0.509 ; p=0.003)$. Therefore, decreasing latitude was associated with a significantly higher incidence of disease. Furthermore, a positive and near-significant PCC was observed between the CIR and longitude $(\mathrm{r}=0.347 ; \mathrm{p}=0.055)$, suggesting that increasing longitude is associated with a higher incidence of disease.

A scatter plot with a line of best fit (95\% confidence interval) and calculated coefficient of determination $\left(R^{2}\right)$ is shown in Figure 6.

\section{DISCUSSION}

The average annual incidence of ALL was 2.25 per 100,000 children under the age of 15 years from 2006 to 2014 . Therefore, the incidence of this disease in Iranian children was lower than has been reported in developed countries and similar to that in other developing countries. The incidence of ALL is generally higher in high-income countries with higher Human Development Index [10].

A previous study analyzed the incidence of childhood cancer in 62 countries from 2001 to 2010 and showed that the incidence of leukemia was higher in the United States, Europe, and Oceania than in Asian and African countries. It has been proposed that genetic differences may contribute to differences in the incidence of ALL, which may explain the higher incidence reported in Hispanics [20]. Overall, $4.3 \%$ of leukemia cases are attributed to an inherited genetic predisposition [21].

An analysis of the temporal trend of incident cases of ALL from 2006 to 2014 showed that the incidence of new cases has increased 2.28-fold. Similar findings have been reported in many developing countries, and may reflect the more youthful population structure of these countries [22]. It is estimated that around $70 \%$ of cases will occur in developing countries by 2030 [23].

In the present study, $57.9 \%(n=2,182)$ of cases of ALL were observed in boys, reflecting a sex ratio of males to females of 1.37 .
These results are consistent with other studies, which have generally shown a higher incidence of disease in boys than in girls [4,9,24-26]. According to the American Cancer Society's 2019 report, $55 \%$ of new cases and $56 \%$ of ALL deaths were in boys [27].

In the present study, the age distribution of patients was skewed to the right. The incidence of ALL was higher in children shortly after birth (i.e., when the prevalence of pathogenic microorganisms is higher and children are more susceptible to a variety of infections due to their weaker immune system). As age increased, corresponding to strengthening of the immune system, the incidence of the disease gradually decreased. This observation implies that ALL may have an infectious origin; specifically, it may be due to an abnormal body response to common infections early in life [28-30].

The analysis of new cases based on month of diagnosis showed that ALL had seasonal variations, and that ALL was more likely to occur during the warm season (i.e., spring and summer). These seasonal variations can be considered from two perspectives: First, they are high-risk seasons for the transmission of infectious pathogens because of appropriate environmental conditions. Second, during the warm season, exposure to the sunlight is longer, meaning that exposure to solar ultraviolet (UV) radiation is increased. Both factors have been mentioned in various studies as carcinogens and risk factors for ALL. Furthermore, other studies have also reported that summer and spring were high-risk seasons for the incidence of ALL [29,31]. The seasonal pattern of ALL incidence has also been considered in some studies as a factor supporting the infectious hypothesis $[8,29,32]$.

In a study conducted in Japan, Uehara et al. [33] reported a significant positive correlation between the risk of leukemia death and exposure to solar UVB radiation [33]. Using Poisson regression analysis, Coste et al. [34] found that for every $25 \mathrm{~J} / \mathrm{cm}^{2}$ increase in solar UV radiation in children under 5 years of age, the standardized incidence rate of ALL increased significantly. Overall, there was a linear trend for solar UV radiation exposure in different geographic regions to be associated with an increase in leukemia incidence. The researchers suggested that suppression 
of the immune system by UV radiation may be a biological hypothesis for this finding [34].

The spatial pattern analysis showed that ALL in Iran tended to show a high spatial autocorrelation and spatial clustering, which was more intense for high rates of incidence (hot spots). The emergence of clusters in the spatial incidence of ALL has been recognized as a supporting factor for the influence of environmental risk factors, and especially infectious pathogens, on the disease cycle [7,9,13-16]. Among the predisposing, enabling, and reinforcing factors that lead to the occurrence of leukemia, some researchers suspect that viruses (e.g., hepatitis B virus, hepatitis $C$ virus, hepatitis $\mathrm{G}$ virus, and human T-cell leukemia virus type 1). These viruses may contribute to the development of leukemia due to the potential for acute and chronic infections in leukocytes, especially lymphocytes (through their property of lymphotropism) $[35,36]$.

All of the cold spots were located in the north and west of Iran (lower longitude and higher latitude) and all of the hot spots were located in southern, central, and eastern Iran (higher longitude and lower latitude). This clustering is very specific and significant, and may be due to synergistic interactions between environmental and geographic risk factors such as latitude and longitude of residence, severe exposure to solar UV radiation, and living in the oil-rich and gas-rich areas of southern Iran.

Children's residence can serve as a reasonable proxy for environmental and local exposure, as children spend large amounts of time at home and have a low relocation rate [5]. One reason for the high incidence of ALL at low latitudes may be direct sunlight, which results in longer and more severe exposure to UV as a carcinogen that contributes to ALL. Coste et al. [34] clearly indicated that the increasing intensity of sunlight at low latitudes led to increased exposure to solar UV radiation, consequently elevating the risk of leukemia [34]. The results of the present study are in line with the results of a population-based study of childhood cancer on the Asian continent. The age-standardized incidence rate of leukemia in 0- to 14-year-old children increased with increasing longitude from West Asia to East Asia (45.2 vs. 47.4 per million person-years). The highest incidence was found in Southeast Asia, corresponding to lower latitudes (52.7 per million person-years) [20].

Another reason for the high incidence of ALL and high-risk clusters in the south of Iran could be the abundance of gas and oil resources, and the consequent high concentrations of benzene and other petroleum hydrocarbons in these areas; this possibility was recently investigated in 2 studies in 2016 and 2017 and these chemicals were reported to be a potential risk factor for leukemia [37,38].

The incidence of ALL in Iranian children is lower than that of developed countries but similar to that of developing countries. The incidence of ALL was higher in the early years after birth (peaking at age 3), when the prevalence of infections is higher and children have weaker immune systems. Given the results of the current study, including the high incidence of ALL during early years of life, seasonal variations, the tendency for high spatial autocorrelation and spatial clustering, and the significant correlation with geographical coordinates-as well as drawing upon the results of other studies-we can conclude that ALL incidence is likely to result from synergistic interactions among environmental, infectious, geographical, and genetic risk factors.

\section{CONFLICT OF INTEREST}

The authors have no conflicts of interest to declare for this study.

\section{FUNDING}

This work was supported by Shahid Beheshti University of Medical Sciences (SBUMS).

\section{ACKNOWLEDGEMENTS}

This article was based on the results of a $\mathrm{PhD}$ thesis in epidemiology.

We would like to thank the Deputy of Research and Technology of Shahid Beheshti University of Medical Sciences, the Ministry of Health and Medical Education of Iran, the Statistical Center of Iran, and the Remote Sensing and GIS Research Center of Shahid Beheshti University whose assistance was crucial to the implementation of this study. Receiving support from the Center of Excellence in Analysis of Spatio-Temporal Correlated Data at Tarbiat Modares University is acknowledge.

\section{AUTHOR CONTRIBUTIONS}

Conceptualization: SRP, AK, BM, AS, KE. Data curation: SRP, KE. Formal analysis: SRP, AK, BM, KE. Funding acquisition: KE. Methodology: SRP, AK, BM, KE. Project administration: SRP, KE. Visualization: SRP, AK, BM, KE. Writing - original draft: SRP, AK, BM, AS, KE. Writing - review \& editing: SRP, AK, BM, AS, KE.

\section{ORCID}

Sajjad Rahimi Pordanjani: http://orcid.org/0000-0002-2359-0037; Amir Kavousi: http://orcid.org/0000-0003-3922-0564; Babak Mirbagheri: http://orcid.org/0000-0002-4161-1540; Abbas Shahsavani: http://orcid.org/0000-0003-3805-6256; Koorosh Etemad: http://orcid.org/0000-0002-4005-9563

\section{REFERENCES}

1. Yano Y, Schiffman C, Grigoryan H, Hayes J, Edmands W, Petrick $\mathrm{L}$, et al. Untargeted adductomics of newborn dried blood spots identifies modifications to human serum albumin associated with childhood leukemia. Leuk Res 2020;88:106268.

2. Ministry of Health and Medical Education. Annual report of Ira- 
nian national population - base cancer registry; 2014. Tehran: Ministry of Health and Medical Education; 2018, p. 312 (Persian).

3. Hayati H, Kebriaeezadeh A, Ehsani MA, Nikfar Sh, Mehrvar A. Cost-analysis of treatment of pediatrics acute lymphoblastic leukemia based on ALL-BFM protocol. Int J Pediatr 2016;4:33813389.

4. Cárceles-Álvarez A, Ortega-García JA, López-Hernández FA, Orozco-Llamas M, Espinosa-López B, Tobarra-Sánchez E, et al. Spatial clustering of childhood leukaemia with the integration of the Paediatric Environmental History. Environ Res 2017;156: 605-612.

5. Konstantinoudis G, Kreis C, Ammann RA, Niggli F, Kuehni CE, Spycher BD, et al. Spatial clustering of childhood leukaemia in Switzerland: a nationwide study. Int J Cancer 2017;141:1324-1332.

6. Ye X, Torabi M, Lix LM, Mahmud SM. Time and spatial trends in lymphoid leukemia and lymphoma incidence and survival among children and adolescents in Manitoba, Canada: 1984-2013. PLoS One 2017;12:e0175701.

7. Birch JM, Alexander FE, Blair V, Eden OB, Taylor GM, McNally RJ. Space-time clustering patterns in childhood leukaemia support a role for infection. Br J Cancer 2000;82:1571-1576.

8. Schmiedel S, Blettner M, Kaatsch P, Schüz J. Spatial clustering and space-time clusters of leukemia among children in Germany, 1987-2007. Eur J Epidemiol 2010;25:627-633.

9. Tlacuilo-Parra A, Garibaldi-Covarrubias R, Romo-Rubio H, Soto-Sumuano L, Ruiz-Chávez CF, Suárez-Arredondo M, et al. Geographical distribution and cluster detection of childhood leukemia in the metropolitan area of Guadalajara, Mexico. Rev Invest Clin 2017;69:159-165.

10. Hubbard AK, Spector LG, Fortuna G, Marcotte EL, Poynter JN. Trends in international incidence of pediatric cancers in children under 5 years of age: 1988-2012. JNCI Cancer Spectr 2019;3:pkz007.

11. Hjalmars U, Kulldorff M, Gustafsson G, Nagarwalla N. Childhood leukaemia in Sweden: using GIS and a spatial scan statistic for cluster detection. Stat Med 1996;15:707-715.

12. Westermeier T, Michaelis J. Applicability of the Poisson distribution to model the data of the German Children's Cancer Registry. Radiat Environ Biophys 1995;34:7-11.

13. Bellec S, Hémon D, Rudant J, Goubin A, Clavel J. Spatial and spacetime clustering of childhood acute leukaemia in France from 1990 to 2000: a nationwide study. Br J Cancer 2006;94:763-770.

14. McNally RJ, Alexander FE, Vincent TJ, Murphy MF. Spatial clustering of childhood cancer in Great Britain during the period 19691993. Int J Cancer 2009;124:932-936.

15. Nyari TA, Ottóffy G, Bartyik K, Thurzó L, Solymosi N, Cserni G, et al. Spatial clustering of childhood acute lymphoblastic leukaemia in hungary. Pathol Oncol Res 2013;19:297-302.

16. Agost L. Analysis of spatial-temporal clusters of childhood cancer incidence in the province of Córdoba, Argentina (2004-2013). Arch Argent Pediatr 2016;114:534-543.

17. Rothman KJ, Greenland S, Lash TL. Modern epidemiology. 3rd ed. Philadelphia: Lippincott Williams \& Wilkins; 2008, p. 512-529.

18. Affan M, Syukri M, Wahyuna L, Sofyan H. Spatial statistic analy- sis of earthquakes in Aceh province year 1921-2014: cluster seismicity. Aceh Int J Sci Technol 2016;5:54-62.

19. Lu P, Bai S, Tofani V, Casagli N. Landslides detection through optimized hot spot analysis on persistent scatterers and distributed scatterers. ISPRS J Photogramm Remote Sens 2019;156:147-159.

20. Steliarova-Foucher E, Colombet M, Ries LA, Moreno F, Dolya A, Bray F, et al. International incidence of childhood cancer, 2001-10: a population-based registry study. Lancet Oncol 2017;18:719-731.

21. Bloom M, Maciaszek JL, Clark ME, Pui CH, Nichols KE. Recent advances in genetic predisposition to pediatric acute lymphoblastic leukemia. Expert Rev Hematol 2020;13:55-70.

22. Ferlay J, Soerjomataram I, Ervik M, Dikshit R, Eser S, Mathers C, et al. GLOBOCAN 2012: estimated cancer incidence, mortality and prevalence worldwide in 2012 v1.0; 2013 [cited 2020 Aug 19]. Available from: http://globocan.iarc.fr.

23. Pérez-Cuevas R, Doubova SV, Zapata-Tarres M, Flores-Hernández S, Frazier L, Rodríguez-Galindo C, et al. Scaling up cancer care for children without medical insurance in developing countries: the case of Mexico. Pediatr Blood Cancer 2013;60:196-203.

24. Bahoush G, Nojoomi M. Frequency of cytogenetic findings and its effect on the outcome of pediatric acute lymphoblastic leukemia. Med Arch 2019;73:311-315.

25. Alrudainy LA, Salih HM, Aldorky M. Incidence and pattern of childhood leukaemia in Basrah, Iraq during 2003-2007. Iran J Blood Cancer 2009;2:11-17.

26. Mehrvar N, Abolghasemi H, Rezvany MR, Akbari ME, Saberynejad J, Mehrvar A, et al. Characterizing Iranian pediatric patients with relapsed acute lymphoblastic leukemia through gene expression profiling of common ATP binding cassette transporters subfamily C. J Pediatr Hematol Oncol 2020;42:41-45.

27. Siegel RL, Miller KD, Jemal A. Cancer statistics, 2019. CA Cancer J Clin 2019;69:7-34.

28. Greaves M. A natural history for pediatric acute leukemia. Blood 1993;82:1043-1051.

29. Ross JA, Severson RK, Swensen AR, Pollock BH, Gurney JG, Robison LL. Seasonal variations in the diagnosis of childhood cancer in the United States. Br J Cancer 1999;81:549-553.

30. Richardson RB. Promotional etiology for common childhood acute lymphoblastic leukemia: the infective lymphoid recovery hypothesis. Leuk Res 2011;35:1425-1431.

31. Gilman EA, Sorahan T, Lancashire RJ, Lawrence GM, Cheng KK. Seasonality in the presentation of acute lymphoid leukaemia. $\mathrm{Br} \mathrm{J}$ Cancer 1998;77:677-678.

32. Karimi M, Yarmohammadi H. Seasonal variations in the onset of childhood leukemia/lymphoma: April 1996 to March 2000, Shiraz, Iran. Hematol Oncol 2003;21:51-55.

33. Uehara M, Takahashi K, Hoshuyama T, Pan G, Feng Y. Geographical correlation between ambient UVB level and mortality risk of leukemia in Japan. Environ Res 2003;92:78-84.

34. Coste A, Goujon S, Boniol M, Marquant F, Faure L, Doré JF, et al. Residential exposure to solar ultraviolet radiation and incidence of childhood hematological malignancies in France. Cancer Causes Control 2015;26:1339-1349. 
35. Takai S, Tsurumi H, Ando K, Kasahara S, Sawada M, Yamada T, et al. Prevalence of hepatitis B and C virus infection in haematological malignancies and liver injury following chemotherapy. Eur J Haematol 2005;74:158-165.

36. Bagheri K, Yaghobi R, Karimi MH, Mirzaei M, Ramzi M. Determination of serologic and molecular prevalence of hepatitis type $\mathrm{B}, \mathrm{C}$, and $\mathrm{G}$ infections in patients with hematological malignancy in the South of Fars Province, Iran. J Fasa Univ Med Sci 2011;1:
168-174 (Persian).

37. Elliott EG, Trinh P, Ma X, Leaderer BP, Ward MH, Deziel NC. Unconventional oil and gas development and risk of childhood leukemia: assessing the evidence. Sci Total Environ 2017;576:138147.

38. McKenzie LM, Allshouse WB, Byers TE, Bedrick EJ, Serdar B, Adgate JL. Childhood hematologic cancer and residential proximity to oil and gas development. PLoS One 2017;12:e0170423. 